\title{
The Last Gasp
}

"Not everything that counts is counted; not everything that is counted is worth counting." - Albert Einstein

Weight in pounds that a 7-lb human baby would reach at 18 weeks if it grew at the same rate as a commercially raised turkey: 1500

No. of pounds Italian tenor Luciano Pavarotti has lost during a lifetime of yo-yo dieting, according to his ex-manager: 5000

Distance in $\mathrm{km}$ a $60-\mathrm{kg}$ woman would have to walk to burn off the energy from a 2000-calorie Christmas dinner: 40

No. of steps the average Amish man in Ontario takes a day: 18000

Percentage of Amish population of Ontario who are considered obese: 4

Projected number of domestic robots in use worldwide by 2007: 4.1 million No. of ounces in a 7-Eleven Double Gulp soft drink: 64

Percentage increase since 1987 of hospitalizations for eating disorders among girls under the age of 15: 34

Percentage of Canadians who eat the 5 to 10 daily servings of fruits and vegetables recommended in the Canada Food Guide: 36

Approximate percentage of genes that humans share with bananas: 50

No. of kg of bananas consumed annually by the average Canadian: 13.4

Cost of 1.5 litres of Madonna's beverage of choice - Kabbalah water drawn from "special springs

in Canada infused with ancient Kabbalistic meditations, prayers and blessings": US\$4.50

Percentage of world's population who will lack enough clean water by 2025: 67

Amount the Toronto Blue Jays paid first baseman Carlos Delgado for each of the 32 home runs he hit in 2004: US\$615 625

Estimated per capita Gross Domestic Product in Afghanistan: US\$700

Average yearly earnings of a Canadian with a high school education: \$25 477

Estimated amount Canadian-born high school dropout and Dumb and Dumber star Jim Carrey earned in 2004: US\$66 million

No. of citizens of Iraq who would have to pool their share of their country's GDP to equal Carrey's 2004 earnings: 44000

Percentage increase in Botox sales in the third quarter of 2004: 25

No. of health-care dollars spent on prescription drugs: 1 in 6

Percentage of revenues Canadian pharmaceutical companies promised to spend on the research and development of new drugs in exchange for the Mulroney government's tightening of drug-patent legislation: 10

Percentage spent in 2003, the eighth consecutive year in which research-to-sales ratios have declined: 8.8

Percentage of US consumers who read little or none of the text containing risk information about drugs in print ads, according to an FDA study: 73

Rank of rofecoxib (Vioxx) among the most costly prescription drug recalls in history: 1

Estimated percentage of worldwide pharmaceutical products that are counterfeit, according to WHO: 10

Sales of prescription drugs to Americans by Canadian-based Internet pharmacies: more than US $\$ 1$ billion

Value of British Columbia's annual marijuana crop: \$6 billion

No. of fatalities due to West Nile fever in Canada in 2004: 0

Estimated number of fatalities worldwide since the first recorded traffic death in London, England, in 1896: 30 million

Estimated no. of vehicle-animal collisions in Canada each year, according to Transport Canada: 45000

Chances of dying if your car hits a deer: 1 in 3500

A moose: 1 in 200

No. of shark-attack deaths worldwide in 2003: 4

No. of Canadians who commit suicide annually: 4000

Percentage of American pet owners who buy their pet a holiday gift: 97

Percentage of those who have returned a gift because their pet didn't like it: 12

No. of broken arms caused by party-cracker-pulling mishaps reported by British hospitals in recent years: 4

Number of Americans treated annually in emergency departments

for injuries sustained putting up holiday decorations: 12800 